
irradiância. Horticultura Brasileira 24: 289-294.

\title{
Crescimento e metabolismo em artemísia em função do nível de irradiância ${ }^{1}$
}

\author{
Luciana M de Carvalho²; Vicente Wagner D Casali³; Suzana Patrícia Lisboa ${ }^{3}$; Luiz Claúdio de A Barbo- \\ $\mathbf{s a}^{3}$; Paulo Roberto Cecon ${ }^{3}$ \\ ${ }^{2}$ Embrapa Tabuleiros Costeiros, C. Postal 44, 49025-040 Aracaju-SE; ${ }^{3}$ UFV, 36570-000 Viçosa-MG; E-mail: luciana@cpatc.embrapa.br
}

\section{RESUMO}

Artemísia [Tanacetum parthenium (L.) Schultz-Bip.] é uma planta medicinal fortemente aromática, cujo princípio ativo característico é a lactona sesquiterpênica partenolídeo. Entre os fatores que afetam o cultivo das plantas medicinais destaca-se a irradiância luminosa. O presente trabalho teve por objetivo verificar efeitos de três níveis de irradiância luminosa $\left(730,523\right.$ e $382 \mu$ mol de fótons $\left.\mathrm{m}^{-2} \mathrm{~s}^{-1}\right)$ na altura, área foliar, número de folhas, teor de açúcares, de amido e de partenolídeo em artemísia. As plantas cresceram a pleno sol e com 30 e 50\% de redução na irradiância por 105 dias. A redução na irradiância foi obtida por meio de sombreamento artificial, com a utilização de telas de polietileno pretas. A redução na irradiância incidente causou aumento na altura e na área foliar total de cada planta, mas não alterou o número de folhas. Houve diminuição nos teores de açúcares e de amido em função do sombreamento, mas os teores de partenolídeo não foram alterados significativamente.

Palavras-chave: Tanacetum parthenium, sombreamento, plantas medicinais, açúcares solúveis, amido, partenolídeo.

\begin{abstract}
Growth and metabolism of feverfew plants in response to the irradiance level

Feverfew [Tanacetum parthenium (L.) Schultz-Bip.] is a strongly aromatic medicinal plant, whose active principle is the sesquiterpene lactone parthenolide. Irradiance ranks among the most important factors that affect growth of medicinal plants. The effect of three irradiance levels $\left(730,523\right.$ and $382 \mu \mathrm{mol}$ of fotons $\left.\mathrm{m}^{-2} \mathrm{~s}^{-1}\right)$ were assessed on feverfew plants height, leaf area, and leaf number, as well as on the contents of sugar, starch, and parthenolide. Plants grew on full sunshine and under 30 and $50 \%$ of irradiance reduction, for 105 days. Irradiance was controlled by shadowing plants with a black polyethylene screen. Reduction on irradiance increased plant height and total leaf area, but had no effect on leaf number. A reduction in sugar and starch contents in association with shadowing was observed. Nevertheless, shadowing did not affect significantly the parthenolide content.
\end{abstract}

Keywords: Tanacetum parthenium, shadowing, medicinal plants, soluble sugars, starch, parthenolide.

\section{(Recebido para publicação em 23 de fevereiro de 2005; aceito em 29 de agosto de 2006)}

$\mathrm{N}^{a}$ as últimas décadas têm-se testemunhado o retorno ao uso de plantas medicinais e seus derivados, em função dos altos preços dos medicamentos quimio-sintéticos e da busca por uma vida mais saudável. A artemísia ou artemigem, Tanacetum parthenium (L.) Schultz.-Bip., é uma planta fortemente aromática, que nos últimos 20 anos, tem recebido considerável atenção, em razão de suas propriedades profiláticas com respeito à freqüência e severidade dos ataques de enxaqueca (Hewlett et al., 1996; Weber et al., 1997). O constituinte químico característico e responsável pelo seu efeito terapêutico é o partenolídeo, uma lactona sesquiterpênica, presente na parte aérea dessas plantas (Bohlmann \& Zdero, 1982; Begley et al., 1989; Rey et al., 1992; Hendriks et al., 1996; Hewlett et al., 1996; Brown et al., 1997).

A demanda crescente por plantas medicinais torna o cultivo cada dia mais importante. Na produção de plantas medicinais há aspectos intrínsecos, ambientais e técnicos que influem na área cultivada e, consequentemente, na produção de metabólitos pela planta e na utilização destes na elaboração de princípios ativos (Ming, 1994). A luz como fonte primária de energia é um dos principais fatores, relacionados à produtividade fotossintética, a ser considerado.

As respostas das plantas à redução da intensidade luminosa são muitas e variadas. Essencialmente há duas estratégias para enfrentar a condição de sombreamento: alterar o processo de crescimento e desenvolvimento e, assim, evitar o sombreamento, ou tolerar e manter o padrão de crescimento (Smith \& Whitelam, 1997). Em geral, a baixa intensidade de luz resulta em diminuição na taxa de fotossíntese, na biomassa e na produção, podendo ainda afetar o transporte de fotoassimilados e a relação fonte:dreno (Souza et al., 1999). No entanto, a plasticidade adaptativa das espécies vegetais à radiação solar depende do ajuste do aparato fotossintético, a fim de possibilitar conversão altamente eficiente de energia radiante em carboidratos e consequentemente promover maior crescimento (Alvarenga et al., 2003).

Este trabalho teve por finalidade verificar os efeitos de três níveis de irradiância luminosa na altura, área foliar, número de folhas, teor de açúcares solúveis, de amido e de partenolídeo em plantas de artemísia.

\section{MATERIAL E MÉTODOS}

Plantas de artemísia, Tanacetum parthenium (L.) Schultz.-Bip, foram obtidas de sementes cedidas pelo Grupo Entre Folhas, localizado em Viçosa, MG. Aproximadamente dois meses após semeadura em bandejas de isopor, plan-

${ }^{1}$ Trabalho executado com apoio do CNPq, como parte de tese de doutoramento em fitotecnia na Universidade Federal de Viçosa, Viçosa-MG. 
tas com cerca de $0,11 \mathrm{~m}$ e com 15 folhas, em média, foram plantadas em vasos de dez litros, preenchidos com substrato constituído por terra:areia:esterco bovino decomposto, na respectiva proporção de 3:2:1. Amostras do substrato dos vasos foram analisadas na Universidade Federal de Viçosa (UFV), resultando em boa disponibilidade de bases trocáveis (valor de soma de bases, $\mathrm{SB}=6,02 \mathrm{cmol} \mathrm{dm}^{-3}$ e de saturação de bases, $\mathrm{V}=78 \%$ ) e ótima disponibilidade de fósforo (268 $\left.\mathrm{mg} \mathrm{dm}^{-3}\right)$.

$\mathrm{O}$ experimento foi conduzido no viveiro de plantas ornamentais da UFV, em Viçosa $\left(20^{\circ} 45^{\prime} \mathrm{S}, 650 \mathrm{~m}\right.$ de altitude), segundo esquema de parcelas subdivididas, tendo nas parcelas três níveis de irradiância luminosa incidente (730, 523 e $382 \mu \mathrm{mol}$ de fótons $\mathrm{m}^{-2} \mathrm{~s}^{-1}$, em média), que corresponderam à exposição da planta a pleno sol e a 30 e $50 \%$ de sombreamento. $\mathrm{O}$ sombreamento foi obtido com tela plástica de polietileno preta. Nas subparcelas foram alocadas seis épocas de colheita $(30,45,60,75$, 90 e 105 dias após início do sombreamento das plantas). O delineamento utilizado foi blocos ao acaso, com quatro repetições, sendo cada parcela constituída por seis vasos e, cada subparcela, por um vaso.

As épocas de colheita da parte aérea das plantas foram determinadas a partir dos resultados de Hendriks et al. (1997) e de Figueiredo (1998) com plantas de artemísia, considerando que o estádio de desenvolvimento das plantas poderia afetar não só o crescimento, mas também os teores de partenolídeo e de açúcares solúveis e insolúveis disponíveis na parte aérea. As plantas foram secas à temperatura ambiente e a umidade do ar foi mantida em torno de $50 \%$ (câmara seca), por meio de desumidificador comercial, com capacidade de $18 \mathrm{~L} \mathrm{dia}^{-1}$ em $280 \mathrm{~m}^{3}$, circulação $600 \mathrm{~m}^{3}$ hora $^{-1}$, motor 390 watts e 110 volts, durante cerca de 20 dias.

O crescimento das plantas foi monitorado por meio de medições periódicas da altura média das plantas, número de folhas e da área foliar total de cada planta. As primeiras medições foram realizadas no dia em que implementou-se o regime de sombreamento, denominado dia zero.
$\mathrm{Na}$ determinação da área foliar utilizou-se análise de regressão múltipla para estimar a equação ( $\mathrm{Y}=$ $4,46065+1,15393 C-0,0241692 C^{2}-$ $5,03714 \mathrm{~L}+0,701271 \mathrm{~L}^{2}+0,192815 \mathrm{CL}$, cujo coeficiente de determinação foi $\mathrm{r}^{2}=$ $0,9169)$ que mais se ajustasse aos dados. Para isso, antes de iniciar o experimento propriamente dito, foram feitas medições de comprimento e maior largura das lâminas foliares maiores e de dimensão média em cerca de doze plantas de artemísia, em três estádios de desenvolvimento. As medidas foram tomadas utilizando-se régua milimetrada. A área destas mesmas lâminas foliares foi avaliada por meio do medidor de área foliar portátil Li-cor, modelo 3000. Posteriormente, no decorrer do período experimental, foi possível estimar, em cada época de colheita, a área da folha maior e da folha de dimensão média, sem precisar retirá-las das plantas, por meio da equação de regressão obtida e de medidas de comprimento (C) e largura (L) máximas dessas lâminas foliares. A área foliar total foi, em seguida, estimada multiplicando-se a área foliar média de cada planta pelo número de folhas (Figueiredo, 1998; Carvalho, 2001).

Em todas as épocas determinou-se o teor de açúcares solúveis totais, redutores, não redutores e de amido nas folhas do terço superior das plantas. A determinação de açúcares e amido foi feita a partir de amostras foliares de 300 $\mathrm{mg}$ retiradas das folhas expandidas do $2^{\text {o. }}$ e $3^{\text {o. }}$ nó a partir do ápice (Carvalho, 2001), segundo procedimento adotado por Gomes (2000). A determinação do teor de açúcares solúveis totais foi realizada com alíquotas desse extrato e reação com antrona (Hodge \& Hodfreiter, 1962). O teor de açúcares redutores foi determinado conforme metodologia descrita por Nelson (1944) e adaptada por Somogy (1952). O teor de açúcares nãoredutores foi estimado por meio da diferença entre o teor de açúcares solúveis totais e o de açúcares solúveis redutores.

$\mathrm{Na}$ extração de amido foi utilizado o resíduo proveniente da extração de açúcares solúveis totais, ressuspendido em 5,75 mL de ácido perclórico a 30\% e mantido em repouso por 30 minutos, com agitações ocasionais. A suspensão foi, então, centrifugada a $3000 \times \mathrm{x}$ du- rante dez minutos. Esse procedimento foi repetido por mais duas vezes, sendo o precipitado descartado e os sobrenadantes combinados. $\mathrm{O}$ volume final foi ajustado com água destilada para $50 \mathrm{~mL}$. A determinação do teor de amido foi feita em alíquota do extrato, por meio da reação com antrona (McCready et al., 1950, citado por Gomes, 2000).

A extração do partenolídeo, a partir da parte aérea das plantas (folhas, botões florais e inflorescências), foi realizada de acordo com método descrito por Brown et al. (1997; 1999), com adaptações de Carvalho (2001). Após moagem de folhas e inflorescências, amostras de $200 \mathrm{mg}$ da parte aérea das plantas foram homogeneizadas em clorofórmio e em seguida, submetidas a banho-maria com ultra-som, por 15 minutos, para extração do partenolídeo. Posteriormente, esse extrato foi filtrado e levado ao evaporador rotativo a $38^{\circ} \mathrm{C}$, para eliminação do solvente. As condições de determinação do teor de partenolídeo em cada amostra foram similares às descritas por Hendriks et al. (1997).

Os extratos foram analisados por cromatografia gasosa, utilizando-se aparelho Shimadzu, modelo GC - 17A, equipado com detector de ionização de chama, acoplado a registrador e integrador C-R6A Cromatopac. A coluna utilizada foi a capilar SBP-5 (Supelco), com $30 \mathrm{~m}$ de comprimento por $0,25 \mathrm{~mm}$ de diâmetro interno e filme com espessura de $0,25 \mu \mathrm{m}$. O gás carreador foi o nitrogênio. As temperaturas utilizadas no injetor $\left(270^{\circ} \mathrm{C}\right)$ e no detector $\left(300^{\circ} \mathrm{C}\right)$ foram definidas em testes preliminares. A temperatura da coluna durante a extração aumentou de 220 a $250^{\circ} \mathrm{C}$, com isoterma de dez minutos em $250^{\circ} \mathrm{C}$.

As amostras do extrato foram precisamente pesadas $(10 \mathrm{mg})$ e diluídas em clorofórmio, sendo injetado $1 \mu \mathrm{L}$. Nas alíquotas $(1 \mu \mathrm{L})$ do extrato total, o teor de partenolídeo foi quantificado por referência com curva-padrão. O teor de partenolídeo nas amostras foi expresso por planta individual, em relação a massa seca da parte aérea (em miligrama) e em porcentagem $(\mathrm{m} / \mathrm{m})$ de massa seca.

Os dados obtidos foram analisados utilizando-se técnica de superfície de 
resposta. Os modelos foram escolhidos baseando-se na significância do teste t, a $5 \%$ de probabilidade, e no coeficiente de determinação.

\section{RESULTADOS E DISCUSSÃO}

A redução na irradiância causou aumento na altura média das plantas de artemísia, em função do tempo após início do sombreamento. Enquanto as plantas crescidas por 105 dias em ambiente com 30 ou $50 \%$ de sombreamento alcançaram, em média, 0,92 m e 1,06 m, respectivamente (Figura 1a), as plantas mantidas a pleno sol atingiram cerca de $0,76 \mathrm{~m}$ de altura. Portanto, considerando-se as médias obtidas no nível de maior irradiância como referência, houve aumento em torno de 21 e $39 \%$, respectivamente, na altura média das plantas crescidas a 30 e $50 \%$ de sombreamento. Apesar das reações ao sombreamento serem diversas, o estímulo no crescimento em altura é uma das respostas mais características e rápidas ao sombreamento (Morelli \& Ruberti, 2000). Essencialmente, as plantas são capazes de evitar ou tolerar o sombreamento. As espécies que respondem ao sombreamento com maior crescimento em altura são capazes de escapar às alterações mais prejudiciais causadas pelo sombreamento (Taiz \& Zeiger, 1998; Morelli \& Ruberti, 2000). Esse é o caso da sálvia (Salvia officinalis) e do tomilho (Thymus vulgaris) que, à semelhança da artemísia, tiveram maior crescimento em altura quando submetidos a sombreamento (Li et al., 1996).

O número de folhas nas plantas de artemísia não foi modificado em função do nível de irradiância. No entanto, a área foliar total de cada planta (Figura 1b) variou, sendo maior nas plantas crescidas nos menores níveis de irradiância. O valor máximo de área foliar $\left(1,14 \mathrm{~m}^{2}\right)$, estimado fixando-se o nível de irradiância, foi alcançado 64 dias após início do sombreamento, pelas plantas submetidas a $50 \%$ de redução de irradiância. Nesse mesmo dia, as plantas crescidas a $30 \%$ de sombreamento alcançaram área foliar de 1,04 $\mathrm{m}^{2} \mathrm{e}$, as que se desenvolveram a pleno sol, 0,89 $\mathrm{m}^{2}$. Assim, adotando como referência a

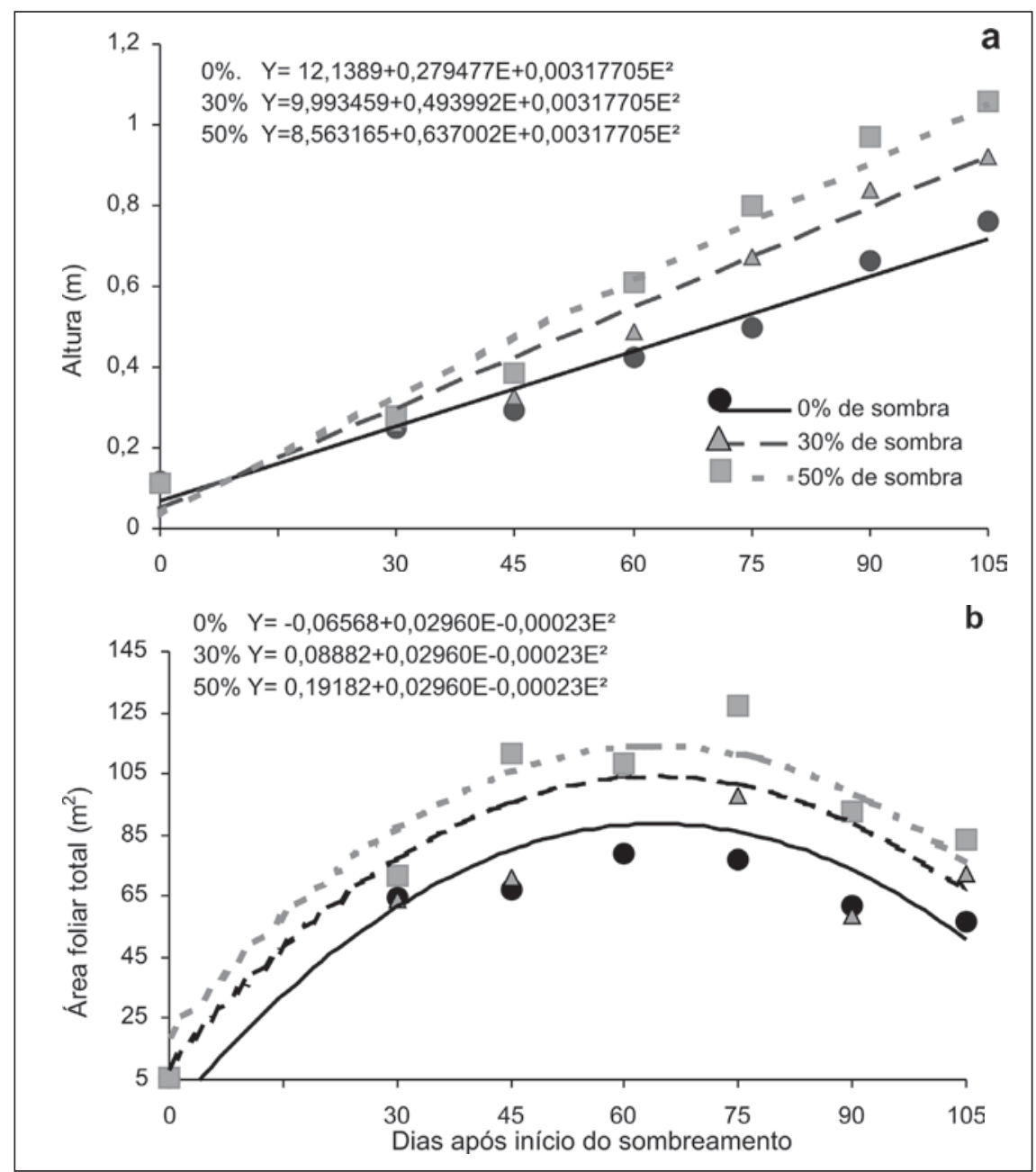

Figura 1. Altura (a) e área foliar total por planta (b) de artemísia, em função do tempo e da intensidade de sombreamento. Viçosa, UFV, 2006.

média de área foliar das plantas crescidas a pleno sol, as plantas crescidas com $50 \%$ de sombreamento tiveram, 64 dias após o início do sombreamento, incremento de $28 \%$ e $39 \%$ em área foliar e altura respectivamente. Plantas de trigo, de pitanga, de Croton urucurana Baill e da invasora Ischaemum rugosum tiveram maior área foliar quando cresceram sob sombreamento artificial (Friend \& Pomeroy, 1970; Marenco \& Reis, 1998; Scalon et al., 2001; Alvarenga et al., 2003). O aumento da área foliar decorre de ampliação da superfície fotossintetizante na planta visando maximização da absorção luminosa (Scalon et al., 2001). Em geral, folhas sombreadas podem ter área superficial 20 a $80 \%$ maior do que folhas crescidas ao sol (Nobel, 1991). A redução no nível de radiação incidente induziu as plantas a investirem maior proporção dos seus recursos no cresci- mento em altura e em área foliar. $\mathrm{O}$ aumento na área foliar total pode decorrer tanto de aumento na expansão celular, quanto de aumento no número de divisões celulares ao longo da lâmina foliar (Friend \& Pomeroy, 1970).

A redução na área foliar total das plantas, verificada nas últimas épocas de colheita, provavelmente ocorreu devido tanto à perda das folhas senescentes (folhas mais basais), quanto à redução nas dimensões das folhas. Isto porque a metodologia de área foliar total por planta considerou não apenas o número de folhas em cada planta, mas também a dimensão.

A redução na irradiância luminosa incidente nas plantas de artemísia não alterou significativamente o acúmulo de massa fresca e seca da planta inteira (dados não apresentados), apesar de ter causado aumento significativo na altura e na área foliar total de cada planta (Fi- 

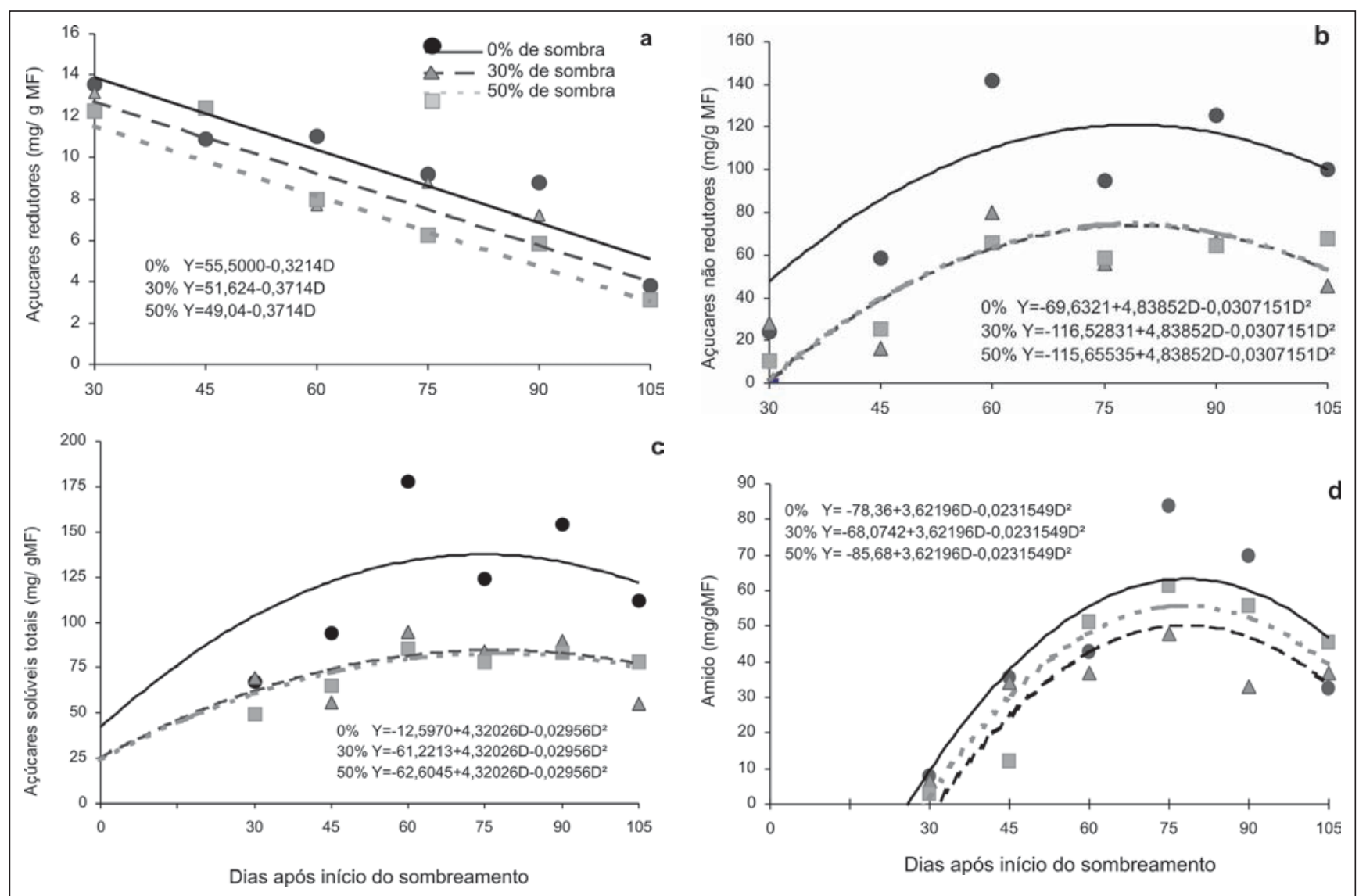

Figura 2. Teor de açúcares solúveis redutores (a), não-redutores (b), totais (c) e de amido, em miligrama por grama de massa fresca (mg g ${ }^{-1}$ MF), nas folhas expandidas do $2^{\circ}$ e $3^{\circ}$. nós das plantas de artemísia, em função do tempo e da intensidade de sombreamento. Viçosa, UFV, 2006.

gura 1) e diminuição no teor de açúcares solúveis e totais das folhas (Figura 2). Diminuição nos teores de açúcares solúveis e de amido ocorrem em decorrência de reduções na taxa fotossintética (Kasperbauer, 1994; Dubey \& Pessarakli, 1995).

Os teores de açúcares solúveis redutores, não-redutores, totais e de amido foram maiores nas plantas mantidas a pleno sol durante todo seu desenvolvimento (Figura 2). Fixando-se o nível de irradiância, verificou-se maior teor de açúcares solúveis totais (Figura 2c) 73 dias após início do experimento nas plantas a pleno sol (145,3 mg de açúcar por grama de massa fresca). Nesta mesma data, as plantas crescidas em $30 \%$ de sombreamento tiveram $96,6 \mathrm{mg}$ e, as crescidas a 50\%, tiveram 95,2 mg de açúcar por grama de massa fresca. Da mesma forma, maior teor de açúcares redutores, monossacarídeos simples como a glicose (Figura 2a), e de açúcares não-redutores (Figura 2b), como a sacarose, principal forma transportável de açúcar, ocorreu nas plantas crescidas a pleno sol. O teor máximo de açúcares não redutores (Figura 2b) ocorreu 79 dias após início do experimento, nas plantas crescidas a pleno sol (120,9 mg $\mathrm{g}^{-1}$ de massa fresca). Nesta mesma data, plantas submetidas a $30 \%$ e $50 \%$ de sombreamento apresentaram, respectivamente, 74,9 mg e 74,0 $\mathrm{mg} \mathrm{g}^{-1}$ de massa fresca.

A redução no teor de açúcares solúveis totais, em função do sombreamento das plantas, deveu-se mais a reduções no acúmulo de açúcares não-redutores (em torno de $38 \%$ ), do que a reduções no acúmulo de açúcares redutores (em torno de 3\%). Portanto, provavelmente, o sombreamento prejudicou mais a partição de fotoassimilados do que a capacidade fotossintética dessas folhas. Marenco \& Reis (1998) verificaram alteração na relação fonte:dreno de plantas de Ischaemum rugosum, invasora de plantios de arroz, sendo que em condições de irradiância mais altas, as raízes foram os drenos preferenciais, enquanto com al- tos níveis de sombreamento, as folhas assumiram este papel. O teor de amido (Figura 2d) também foi máximo nas plantas a pleno sol. Cerca de 78 dias após início do experimento, as plantas que cresceram sem sombreamento continham cerca de $63,3 \mathrm{mg}$ de amido por grama de massa fresca, enquanto aquelas crescidas em $30 \%$ e $50 \%$ de sombreamento, continham, respectivamente, $50,3 \mathrm{mg}$ e $56{\mathrm{mg} \times \mathrm{g}^{-1} \mathrm{de}}$ massa fresca.

Tanto a síntese de sacarose e de amido, quanto a alocação de carbono dentro da planta têm padrões distintos, mas podem mudar rapidamente se as condições ambientais são alteradas (Dickson, 1991). Há marcante redirecionamento do fluxo de fotoassimilados dos órgãos fonte e dos sítios de armazenamento em direção ao crescimento em altura nas plantas capazes de evitar a sombra (Smith \& Whitelam, 1997), o que parece ter acontecido, uma vez que houve incremento na altura e atraso na emissão de botões florais (dados não apresentados). 
O teor de partenolídeo por planta individual não foi alterado significativamente em função dos níveis de irradiância. Na Figura 3 verifica-se que o padrão básico de alteração no teor de partenolídeo, em função do tempo de sombreamento foi semelhante nas três condições de irradiância estudadas, com dois picos máximos de acúmulo de partenolídeo, seguidos por declínio. Resultados similares foram obtidos com óleo essencial em salsa (Porter, 1989).

Considerando $100 \mathrm{~g}$ de massa seca de artemísia, obteve-se, por volta dos 45 dias após início do experimento, nas plantas crescidas a pleno sol, valores máximos de partenolídeo (Figura 3a) quando a área foliar total estava próxima do seu máximo (Figura 1b). Em seguida houve declínio nesses valores. $\mathrm{O}$ segundo pico de aumento no teor de partenolídeo, de menores proporções, ocorreu por volta dos 90 dias após início do experimento, coincidindo com o início do florescimento.

Analisando-se os efeitos do sombreamento na porcentagem de partenolídeo (Figura 3a), verificou-se valor máximo em torno de $1,5 \%$ nas plantas crescidas sob $30 \%$ de sombreamento, enquanto nas plantas mantidas a pleno sol o teor de partenolídeo no início do desenvolvimento chegou a $1,98 \%$, decrescendo, no entanto, com o tempo em dias. Este valor é maior do que o relatado até aqui nessa espécie (Hendricks et al.,1997; Brown et al., 1997). Além disso, nas plantas crescidas sombreadas, houve menor variação no teor de partenolídeo (Figura 3 a e b) durante o crescimento: a análise da declividade das linhas de tendência indica que enquanto o teor de partenolídeo nas plantas a pleno sol diminuiu a cada dia em $0,0129 \%$, nas plantas submetidas a 30 e $50 \%$ de sombreamento essa redução foi de, respectivamente, $0,0054 \%$ e $0,0005 \%$. O papel da intensidade luminosa na síntese de princípios ativos ainda não está bem definido. As poucas informações disponíveis concentram-se no efeito da luz sobre a síntese de óleos essenciais. Similarmente ao observado nas plantas de artemísia 30 dias após início do experimento, Li et al. (1996) obtiveram decréscimos no teor de óleo quando plantas de tomilho (Thymus vulgaris) cresceram sombreadas.

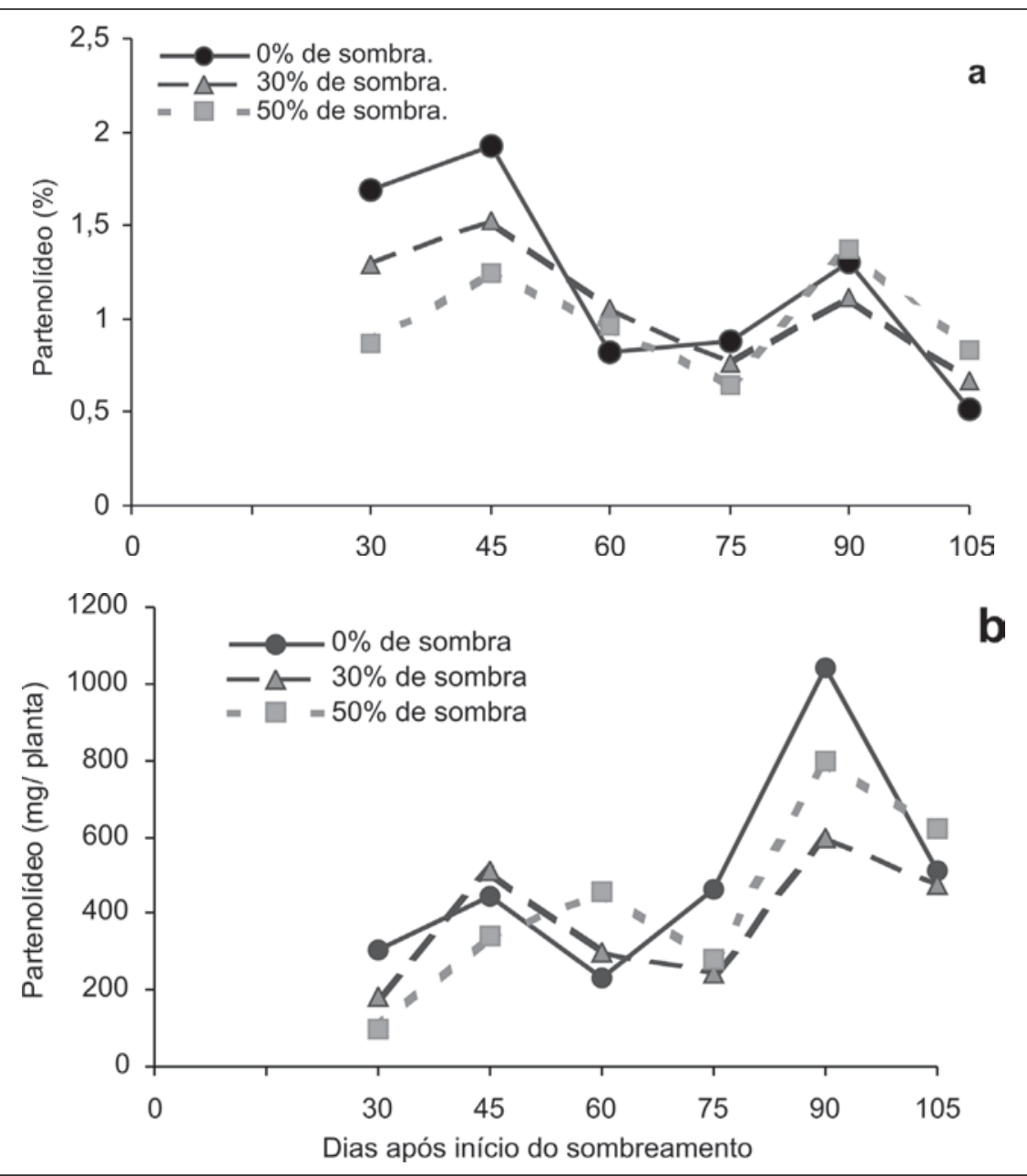

Figura 3. Teor de partenolídeo, em porcentagem (a) e em miligrama por grama (b) de plantas de artemísia secas, em função do tempo e da intensidade de sombreamento. Viçosa, UFV, 2006.

Concluiu-se que, independente do nível de irradiância luminosa incidente, a artemísia, mesmo após o florescimento, continuou com o crescimento em altura até o final do período monitorado. Além disso, os teores de fotoasssimilados solúveis (açúcares redutores, não-redutores e totais), assim como o teor de amido, foram menores nas submetidas ao sombreamento, que tiveram, no mesmo período, maior investimento no crescimento em altura e em área foliar total. Não foi observado efeito significativo do sombreamento sobre os teores de partenolídeos nas plantas estudadas.

\section{REFERÊNCIAS}

ALVARENGA AA; CASTRO EM; LIMA JUNIOR EC; MAGALHÃES M. 2003. / Croton urucurana Baill in southeastern Brazil. Revista Árvore 27: 1-7.
BEGLEY MJ; HEWLETT MJ; KNIGHT DW. 1989. Revised structures for guaianolide amethylenebutyrolactones from feverfew. Phytochemistry 28: 940-943.

BOHLMANN F; ZDERO C.1982. Sesquiterpene lactones and other constituents from Tanacetum parthenium. Phytochemistry 21: 2543-2549.

BROWN AMG; EDWARDS CM; DAVEY MR; POWER JB; LOWE KC. 1997. Effects of extracts of Tanacetum species on human polymorphonuclear leucocyte activity in vitro. Phytotherapy Research 11: 479-484.

BROWN AMG; EDWARDS CM; HARTMANN TTV; MARSHALL JA; SMITH RM; DAVEY MR; POWER JB; LOWE KC. 1999. Sexual hybrids of Tanacetum: biochemical, cytological and pharmacological characterization. Journal of Experimental Botany 50: 435-444.

CARVALHO LM. 2001. Disponibilidade de água, irradiancia e homeopatia no crescimento e teor de partenolídeo em artemísia. Viçosa: UFV. 139p. (Tese doutorado).

DICKSON RE. 1991. Assimilate distribution and storage. In: RAGHAVENDRA AS (ed). Physiology of trees. New York: John Wiley. p. 51-86. 
DUBEY RS; PESSARAKLI M. 1995 Physiological mechanisms of nitrogen absorption and assimilation in plants under stressful conditions. In: PESSARAKLI M (ed). Handbook of plant and crop physiology. New York: Marcel Dekker p. 605-625.

FIGUEIREDO LS. 1998. Germinação e Crescimento de Tanacetum parthenium (L.) Schultz Bip. Viçosa: UFV. 62p.

FRIEND DJC; POMEROY ME. 1970. Changes in cell size and number associated with the effects of light intensity and temperatures on the leaf morphology of wheat. Canadian Journal of Botany 48: 85-90.

GOMES FT. 2000. Crescimento, fotossintese e metabolismo do nitrogênio em alfafa nodulada sob supressão e ressuprimento de fosfato. Viçosa: UFV. 100Op. (Tese doutorado).

HENDRIKS H; BOS R; WOERDENBAG HJ. 1996. The essential oil of Tanacetum parthenium (L.) Schultz-Bip. Flavour and Fragrance Journal 11: 367-371.

HENDRIKS H; ANDERSON-WILDEBOER Y; ENGELS G; BOS R; WOERDENBAG HJ 1997. The content of parthenolide and its yield per plant during the growth of Tanacetum parthenium. Planta Medica 63: 356-359.

HEWLETT MJ; BEGLEY MJ; GROENEWEGEN WA; HEPTINSTALL S; KNIGHT DW; MAY J; SALAN U; TOPLIS D. 1996. Sesquiterpene lactones from feverfew, Tanacetum parthenium: isolation, structural revision, activity against human blood platelet function and implications for migraine therapy. Journal of Chemical Society 1: 1979-1986.
HODGE JE; HODFREITER BR. 1962. Determination of reducing sugars and carbohydrates. In: WHILSTER RL; WOLFROM ML (ed). Methods in carbohydrates chemistry. New York: Academic Press. 1: 380-394.

KASPERBAUER MJ. 1994. Light and plant development. In: WILKINSON RE (ed). Plant-environment interactions. New York: Marcel Dekker. 599p.

LI Y, CRAKER LE, POTTER T. 1996. Effect of light level on essential oil production on sage (Salvia officinalis) and thyme (Thymus vulgaris). Proceedings Int. Symp. Medicinal and Aromatic Plants. Acta Horticulturae 426: 419-426.

MARENCO RA; REIS ACS. 1998. Shading as an environmental factor affecting the growth of Ischaemum rugosum. Revista Brasileira de Fisiologia Vegetal 10: 107-112.

MING LC. 1994. Estudo e pesquisa de plantas medicinais na agronomia. Horticultura Brasileira 12: 3-9.

MORELLI G; RUBERTI I. 2000. Shade avoidance responses. Driving auxin along lateral routes. Plant Physiology 122: 621-626.

NELSON NA. 1944. A photometric adaptation of a method for the determination of glucose. Journal of Biological Chemical 153: 375-380.

NOBEL PS. 1991. Physicochemical and environmental plant physiology. San Diego: Academic Press. 635p.

PORTER NG. 1989. Composition and yield of commercial essential oils from parsley. 1: herb oil and crop development. Flavour and Fragrance Journal 4: 207-219.
REY JP; LEVESQUE J; POUSSET JL. 1992 Extraction and high-performance liquid chromatographic methods for the g-lactones parthenolide (Chrysanthemum parthenium Bernh.), marrubiin (Marrubium vulgare L.) and artemisinin (Artemisia annua L.). Journal of Chromatography 605: 124-128.

SCALON SPQ; SCALON FILHO H; RIGONI MR; VERALDO F. 2001. Germinação e crescimento de mudas de pitangueira (Eugenia uniflora L.) sob condições de sombreamento. Revista Brasileira de Fruticultura 23: 1-5.

SMITH H; WHITELAM GC. 1997. The shade avoidance syndrome: multiple responses mediated by multiple phytochromes. Plant, Cell and Environment 20: 840-844.

SOMOGY M. 1952. Note on sugar determination Journal of Biological Chemistry 95: 19-23

SOUZA JRP; MEHL HO; RODRIGUES JD; PEDRAS JF. 1999. Sombreamento e o desenvolvimento e produção de rabanete. Scientia Agricola 56: 1-9.

TAIZ L; ZEIGER E. 1998. Plant defenses: surface protection and secondary metabolites In: TAIZ L; ZEIGER E. Plant Physiology. Sunderland: Sinauer Associates, 2 ed. p. 350-353.

WEBER JT; O'CONNOR M; HAYATAKA K COLSON N; MEDORA R; RUSSO EB; PARKER KK. 1997. Activity of parthenolide at $5 \mathrm{HT}_{2 \mathrm{~A}}$ receptors. Journal of Natural Products 60: 651-653. 